\title{
Bir Mekanik Montaj Sisteminde Tolerans Yığılması ve Tolerans Alanının Genişletilmesi
}

\section{Tolerance Stacking and Expansion of the Tolerance Area in a Mechanical Assembly System}

\author{
Fikret Sönmez ${ }^{1}$, Şehmus Baday ${ }^{2 *}$ \\ Geliş / Received: 19/02/2021 \\ Revize / Revised: 13/04/2021 \\ Kabul / Accepted: 20/04/2021
}

\section{ÖZ}

Birbiri ile beraber çalışan makine parçalarına tolerans verilmesi gerek fonksiyonellik gerekse maliyet açısından büyük önem taşımaktadır. Özellikle talaşlı imalat ile üretilen makine parçaların için dar tolerans aralıklarının belirlenmesi yüksek maliyet artışlarına neden olmaktadır. Bu nedenle birbiri ile çalışacak makine parçalarının montajının yapılabilmesi ve mümkün olan en geniş tolerans aralığı ile üretilebilmesi istenmektedir. Bu çalışmada, bir mil üzerine standart makine elemanlarının birleştirilmesi ile oluşan bir montaj sistemi analiz edilmiştir. Standart makine elemanları üreticiler tarafından belirli bir tolerans değeri aralığında üretilmektedir. Bu doğrultuda, standart makine elemanlarının toleransları temel alınarak bir mil için toleranslandırma işlemi gerçekleştirilmiştir. Bu birleştirme işleme en kötü durum senaryosu ile başlanmış ve tolerans aralığının genişletilmesi için Monte Carlo simülasyonu ile devam edilmiştir. Yapılan analizler sonucunda en kötü durum senaryosunda elde edilen $\pm 0,015$ $\mathrm{mm}$ tolerans değeri Monte Carlo simülasyonu ile $\pm 0,27 \mathrm{~mm}$ değerine kadar genişletilmiştir. Böylelikle aynı montaj sisteminde çok daha geniş bir tolerans aralığının kullanılmasına ve aynı zamanda maliyetin azaltılması sağlanmıştır.

Anahtar Kelimeler- Toleranslandırma, Mekanik Montaj, En Kötü Durum Senaryosu, Monte Carlo Simülasyon

\begin{abstract}
The tolerance of machine parts working together is of great importance in terms of both functionality and cost. Especially, determining narrow tolerance ranges for machine parts produced by machining causes high cost increases. For this reason, it is desired to be able to assemble machine parts that will work with each other and to be produced with the widest possible tolerance range. In this study, an assembly system formed by combining standard machine elements on a shaft is analyzed. The manufacturers produce standard machine elements within a certain tolerance value range. In this direction, tolerances for a shaft were performed based on the tolerances of standard machine elements. This merging process started with the worst-case scenario and continued with Monte Carlo simulation to extend the tolerance range. As a result of the analysis, the tolerance value of $\pm 0.015 \mathrm{~mm}$ obtained in the worst-case scenario was expanded up to $\pm 0.27 \mathrm{~mm}$ with Monte Carlo simulation. In this way, it is possible to use a much wider tolerance range in the same mounting system and at the same time gain a benefit in cost.
\end{abstract}

Keywords- Tolerancing, Mechanical Assembly, Worst-Case Scenario, Monte Carlo Simulation

1İletișim: sonmezfikret@gmail.com (https://orcid.org/0000-0003-1718-892X)

Makine Mühendisliği Bölümü, Manisa Celal Bayar Üniversitesi, Hasan Ferdi Turgutlu Teknoloji Fakültesi, Manisa, Türkiye

2*Sorumlu yazar iletişim: sehmus.baday@batman.edu.tr (https://orcid.org/0000-0003-4208-8779)

Makine Mühendisliği Bölümü, Batman Üniversitesi, Teknoloji Fakültesi, Batman, Türkiye 


\section{GíRiş̧}

Makine parçaları, bir montaj sistemi içerisinde birbiri ile hem uyumlu hem de ilişkili bir şekilde çalışmaktadır. Montajı oluşturan tüm parçaların birbiri ile olan ilişkileri belirlendikten sonra parçaların imalatı için kullanılacak imalat yöntemi seçilir. Özellikle birbiri arasında dar çalışma boşlukları olan parçalarda ve hassasiyet istenen durumlarda talaşlı imalat sıklıkla tercih edilir [1]. Bundan dolayı, birçok makine parçası, istenilen tolerans aralıklarında talaşlı imalat yöntemi ile üretilmesi mümkündür. Bu parçalara ait üretim maliyeti; iş parçası malzemesi, operasyon türü, kullanılan kesici takımlar gibi birçok faktörden etkilense de çoğunlukla asıl belirleyici faktör parçaların tolerans değeridir. Parçalara ait tolerans değerinin büyük olması kolay ve ekonomik bir imalat imkânı sunmaktadır. Bununla birlikte dar tolerans değerleri hassas tezgâh kullanımı, nitelikli operatör ihtiyacı ve hassas kalite kontrol gibi birçok gerekliliği ortaya çıkartmaktadır. Bu nedenle makine parçalarına tolerans verilirken hem parçaların birbiri ile çalışması sağlayacak hem de mümkün olan en geniş tolerans aralığının kullanılması istenilmektedir. Bu amaçla birçok toleranslandırma tekniği geliştirilmiş̧tir [2, 3].

Bu toleranslandırma yöntemleri arasından kullanılabilecek ilk temel yöntem en kötü durum senaryosudur. $\mathrm{Bu}$ senaryoda bütün hesaplamalar en kötü duruma göre yapılır ve her koşulda montajın yapılması garanti altına alınmış olunur [4, 5]. Fakat bu durum çok dar bir tolerans aralığının oluşmasına sebep olur. Dar bir toleranslandırma aralı̆ğ da parça imalatında büyük maliyetlere yol açmaktadır. Bir diğer yöntem ortalama karelerin karekökü (RSS) yöntemidir. RSS yönteminde üretilecek parçaların boyutsal değişiminin genellikle normal bir dağılım gösterdiği ve bu parçaların çoğunlukla nominal değere yakın üretileceği prensibini temel almaktadır. Talaşlı imalat süreci ile üretilen parçaların büyük çoğunluğu normal bir dağılım gösterdiği bilinmektedir [2, 6]. RSS yöntemi ile tolerans verilecek parçalar için boyutsal olarak aritmetik ortalama ve standart sapma değerleri kullanılmaktadır. Bu durum daha geniş bir tolerans aralığının belirlenmesine sağlarken belli bir hata oranın da kabullenilmesine olanak vermektedir. RSS yöntemine benzer şekilde belirli kurallara bağlı olarak toleranslandırma yapabilecek bir diğer yöntem de Monte Carlo simülasyonu yöntemidir [5]. Monte Carlo yöntemi, RSS yönteminden farklı olarak normal dağılım dışında daha geniş ve farklı bir dağılım aralığında sonuçlar almak mümkündür. Monte Carlo simülasyonu istenen değerleri gerçekleştirmek için verilen aralıkta rasgele değerler üretmektedir. Böylelikle oluşabilecek birçok farklı sonuç senaryoları ortaya çıkarılmış olunur [7]. Her ne kadar birçok çalışmada en kötü durum senaryosu, RSS ve Monte Carlo simülasyonu kullanılsa da toleranslandırma çalışmalarda araştırmacılar tarafından birçok farklı yöntem de uygulanmaya konulmuştur [8]. Araştırmacılar tarafından yapılan bütün toleranslandırma çalışmaları ile parçaların montajı ve bu montajı sağlayacak tolerans değerlerinin tespiti önemli bir konu oluşturmuştur. Yapılan bu çalışmalar aşağıda özetlenmiştir.

Samtaş ve Gülesin yaptıkları çalışmada [9] geliştirdikleri bir bilgisayar yazılımı ile en kötü durum senaryosunu temel alan bir montaj analizi gerçekleştirmiş̧lerdir. Böylelikle mekanik montajların hızlı ve hatasız tolerans verilmesi sağlamışlardır. Toroslu ve Börklü yaptıkları çalışmada [3] genetik algoritma yöntemini kullanarak bir montaj sisteminin analizini gerçekleştirmişlerdir. Bu amaçla montajın gerçekleşmesini sağlayan ve en düşük maliyeti sağlayabilecek tolerans değerlerinin tahminini gerçekleştirmişlerdir. Bayram ve Acar [7] Kriging vekil modeller yaklaşımını Monte Carlo simülasyonu ile birlikte kullanarak bir tolerans analizi çalışması yapmışlardır. Yaptıkları çalışmada bir kavrama montajı ile yöntemin etkinliğini analiz etmişlerdir. Chen ve arkadaşları [10] üç-boyutlu bir toleranslandırma probleminin çözümü üzerine araştırmalar gerçekleştirmişlerdir. Araştırmacılar toleranslandırma analizinde kullanılabilecek birçok yöntemi deneyerek en uygun yöntemin tespitini amaçlamışlardır. Hallmann ve arkadaşları [11] yaptıkları çalışmada bir mekanik montajda ortaya çıkan boşluk değerlerinin maliyet esaslı değerlendirilmesi yapılmıştır. Araştırmacılar bu amaçla aşırı sınırlandırılmış bir kaplin montajı üzerinde araştırmalar gerçekleştirmiştir. Kondic ve arkadaşları [12] yaptıkları çalışmada bir mekanik montaj sisteminin tolerans analizini en kötü durum senaryosu, RSS ve Monte Carlo yöntemi ile analiz etmişlerdir. Denemiş oldukları kavrama montajında RSS ve Monte Carlo yöntemlerinin tolerans aralığını genişlettiğini tespit etmişlerdir.

Bu çalışmada ise standart makine parçaları kullanılarak oluşturulan bir montaj sisteminde yer alan bir mil için toleranslandırma analizi yapılmıştır. Bu amaçla en kötü durum senaryosu ve Monte Carlo simülasyonu ile elde edilen tolerans değerleri imalat maliyetleri ve imalat standartları temel alınarak değerlendirilmiştir. 


\section{MATERYAL VE METOD}

\section{A. Montaj Sistemi}

Bu çalışmada, Şekil 1'de görülen montaj sistemi için bir tolerans analizi gerçekleştirilmiştir. Şekil 1'deki sistem incelendiğinde, mil üzerine iki adet rulman ve bir adet burç kullanılarak bir yataklama yapıldığ görülmektedir. Rulmanların ve burcun konumları bir taraftan mil flanşı diğer taraftan ise emniyet segmanı ile güvenceye alınmıştır. Bu sistem için bir tolerans analizi gerçekleştirilmiş ve iki farklı yöntemle mil için uygun tolerans değerleri analiz edilmiştir.

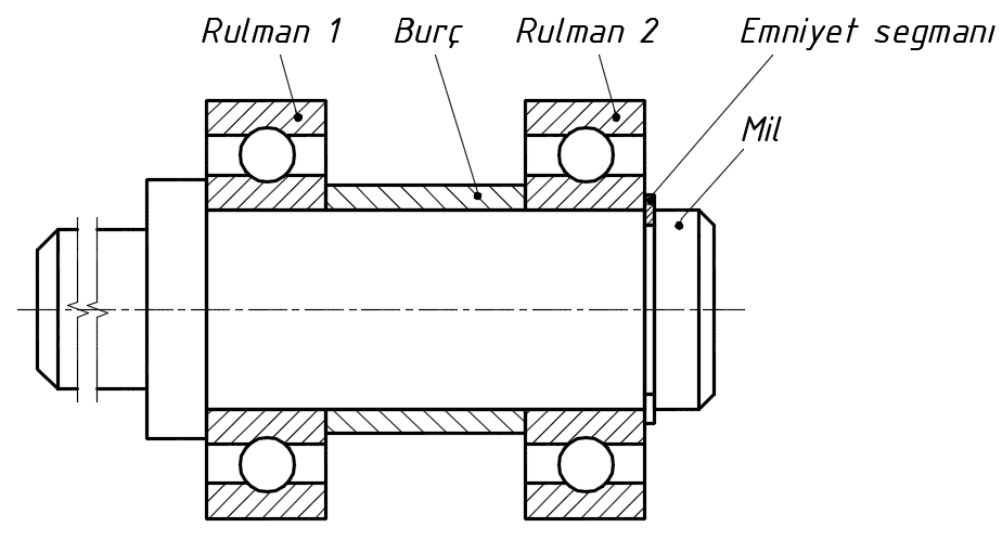

Şekil 1. Montaj sistemi

Rulman ve burç standart makine elemanları olduklarından dolayı bu konstrüksiyonda mil ölçülerine tolerans verilmesi gerekmektedir. Öncelikle kullanılan elemanların çalışma ve montaj şekillerinin analiz edilmesi gerekmektedir. Şekil 2'de bu konstrüksiyonda kullanılan standart elemanlar, montaj sırası ve yataklamanın yapılacağı mil görülmektedir. İlk etapta mil flanşı ile emniyet segmanı arasındaki boşluğun Rulman 1, Burç ve Rulman 2 isimli elemanlarının boyutsal toplamı kadar olması gerektiği düşünülebilir. Kullanılacak standart elemanlardan rulmanların genişliği $12 \mathrm{~mm}$, burcun genişliği ise $20 \mathrm{~mm}$ 'dir (Şekil 2). Bu nedenle milin flanş kısmı ile emniyet segmanı arasındaki bulunan boşluğun nominal ölçüsünün $44 \mathrm{~mm}$ olması gerekmektedir. Bununla birlikte hiçbir makine parçası istenilen tam ölçü ile üretilmesi mümkün olmadığından dolayı standart elemanlarının her birinin boyutsal ölçülerinin de toleransları mutlaka değerlendirilmelidir. Rulmanlar ve Burç için tolerans kavramı düşünüldügüünde ilk akla gelen alıştırma toleranslarıdır. Ayrıca bu standart makine elemanlarının genişlik ölçülerinin de tolerans değerleri önemlidir. Tüm üretim ve montaj işlemlerinde belirlenmiş tolerans değerleri kullanılmaktadır. Bu nedenle mile tolerans verilmesine öncelikle standart elemanlarının toleransları araştırılarak başlanılmıştır.
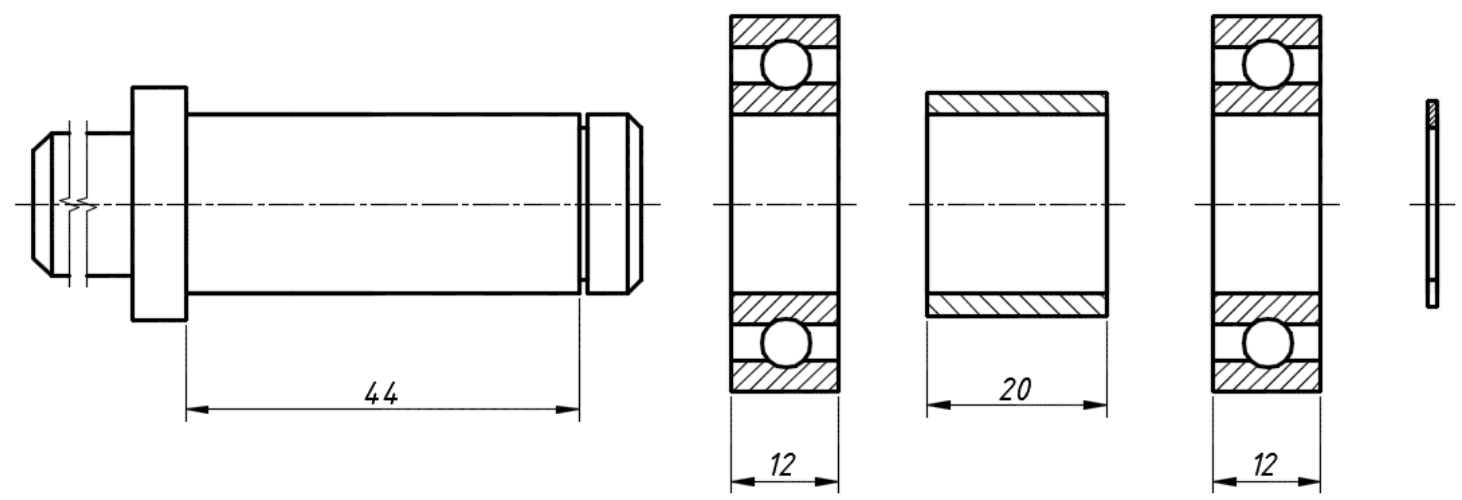

Şekil 2. Parçaların ölçüleri ve montaj sırası 
Rulmanlar birçok farklı sınıfta üretilmekte ve her sınıfın kendine özel bir toleransı bulunmaktadır. Bu çalışmada ise en yaygın kullanıma sahip DIN 625 (TS 6269) standardında 6004 serisi standart (normal sınıf) rulman tercih edilmiştir. Bu rulmana ait boyutsal tolerans değerleri ISO 492 standarttı göz önünde bulundurularak alınmıştır. Kullanılan Burç ise $20 \mathrm{~mm}$ iç çap ölçüsünde ISO 2795 standardına uygun sinterlenmiş bronz Burç (PSM 202520 A51) kullanılmıştır. Üretici firmalardan alınan katalog bilgilerine göre rulman ve burç için genişlik toleransları Tablo 1'de verilmiştir.

Tablo 1. Standart makine elemanların nominal ölçüleri

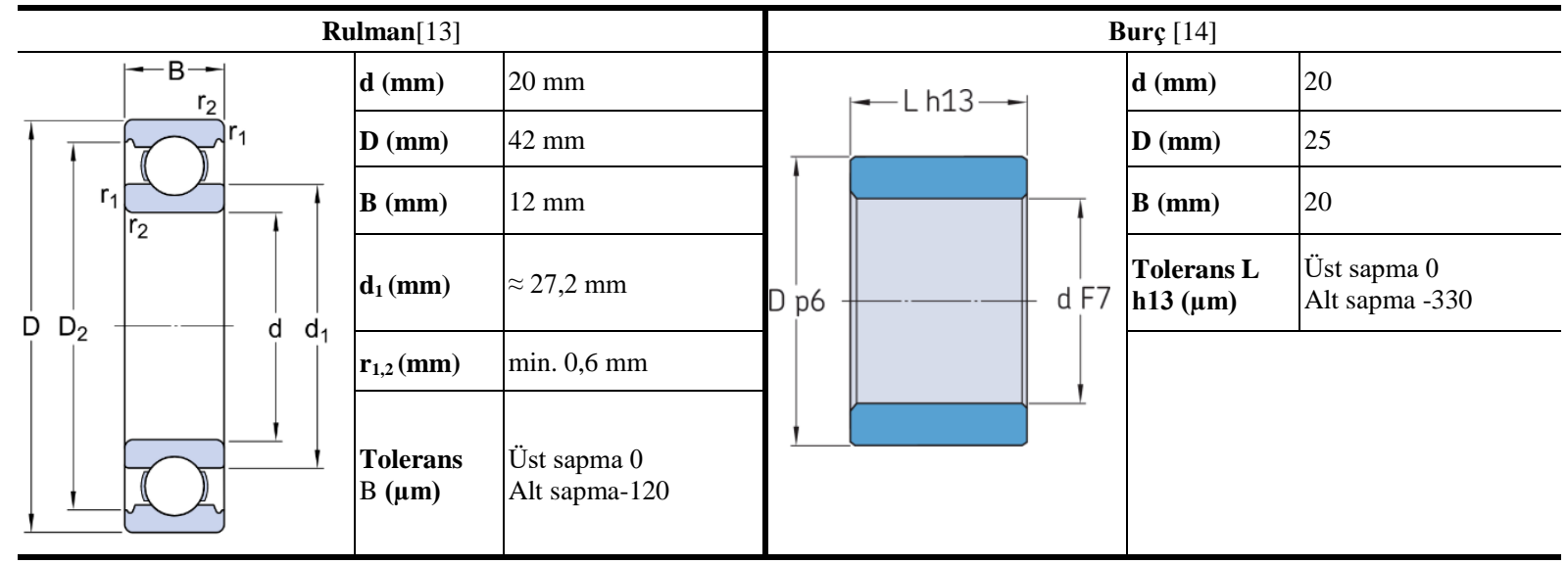

Tablo 1'de verilen ölçüler mil flanşı ile segman arasındaki genişliği belirlemektedir. Bu nedenle standart elemanların alt ve üst sapma değerlerine göz önünde bulundurularak limit değerleri hesaplanmıştır (Tablo 2).

Tablo 2. Standart elemanların limit ölçüleri

\begin{tabular}{l|c|c|c|c}
\hline \multirow{2}{*}{ Standart eleman } & \multicolumn{2}{|c|}{ Tolerans değeri $(\mu \mathrm{m})$} & \multicolumn{2}{c}{ Ölçü Değerleri $(\mathrm{mm})$} \\
\cline { 2 - 5 } & - (Negatif) & + (Pozitif) & Minimum & Maksimum \\
\hline Rulman 1 & -120 & +0 & 11,880 & 12,000 \\
\hline Burç & -330 & +0 & 19,670 & 20,000 \\
\hline Rulman 2 & -120 & +0 & 11,880 & 12,000 \\
\hline
\end{tabular}

Montajın gerçekleştirilebilmesi için emniyet segmanı ile rulman arasında sınırlı bir boşluk bulunmalıdır. $\mathrm{Bu}$ amaçla minimum boşluk değeri $0 \mathrm{~mm}$ olarak belirlenirken, maksimum boşluk değeri talaşlı imalat yolu ile kolayca elde edilebilecek bir değer olan $0,6 \mathrm{~mm}$ olarak belirlenmiştir. Yapılan montaj işleminin gerçekleştirilmesini garanti altına almak için ve belirlenen bu boşluk aralığının $(0 \mathrm{~mm}-0,6 \mathrm{~mm})$ elde edilebilmesi için en kötü durum senaryosu ve Monte Carlo simülasyonu metotları kullanılmıştır.

\section{B. En Kötü Durum Senaryosu}

Montajda bulunan standart elemanların montaja uygun şekilde mile yerleştirilebilmesi amacıyla tolerans yığılması yaklaşımı kullanılmıştır. Bu amaçla tolerans yığılması hesaplamalarında sıklıkla kullanılan [5,9] en kötü durum senaryosu ve kapalı zincir hesaplama (Loop diagram) yöntemi tercih edilmiştir [2]. Bu yöntem her koşulda montajı garanti ettiği ve kolay hesaplanabilir yapısı nedeniyle tercih edilmiştir. Bu yaklaşımda montajı oluşturan elemanlar kapalı bir zincir oluşacak şekilde yerleştirilerek (Şekil 3) gerekli hesaplamalar yapılmaktadır. 


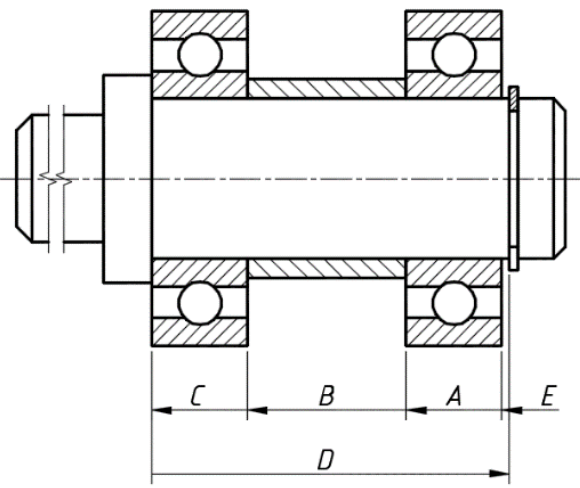

Şekil 3. Kapalı Zincir metodu (Loop Diagram) ile tolerans kontrolü

Rulman ile emniyet segmanı arasındaki boşluk mesafesinin en az $0 \mathrm{~mm}$ en çok $0,6 \mathrm{~mm}$ olması istenmiş ve belirlenen bu boşluk miktarına göre mil için gerekli olan Şekil 3 'te görülen " $D$ ” ölçüsü araştırılmıştır. Zincir hesaplama yönteminde makine parçalarının toleranslar değerleri nominal ölçüye göre eşit dağıtılmaktadır. Böylelikle hesaplama kolaylığı elde edilmektedir. Örneğin rulman ölçüsü $12,000 \mathrm{~mm}(+0,-0,120 \mathrm{~mm})$ olduğundan $11,880 \mathrm{~mm}$ ile $12,000 \mathrm{~mm}$ arası boyutlandırılması gerekmektedir. Hesaplama kolaylığ aritmetik ortalaması alınarak $(11,940 \mathrm{~mm})$ tolerans değeri $\pm 0,060 \mathrm{~mm}$ olarak hesaplanmıştır (Tablo 3 ).

Tablo 3. Toleransların simetrik hale getirilmesi

\begin{tabular}{cccccc}
\hline Parça & Kod & Minimum ölçü (mm) & $\begin{array}{c}\text { Maksimum ölçü } \\
(\mathbf{m m})\end{array}$ & Ortalama ölçü (mm) & Tolerans (mm) \\
\hline Rulman & A & 11,880 & 12,000 & 11,940 & 0,06 \\
\hline Burç & B & 19,670 & 20,000 & 19,835 & 0,165 \\
\hline Rulman & C & 11,880 & 12,000 & 1,940 & $?$ \\
\hline Mil & D & $?$ & 0,600 & 0,300 & $?$ \\
\hline Boșluk & E & 0 & & 0,300 \\
\hline
\end{tabular}

Tablo 3'te verilen değerler referans alınarak mil için tolerans hesaplamaları yapılabilir. Bununla birlikte yapının daha kolay analiz edilebilmesi için birbiri arasında boşluk olmayan elemanlar gruplandırılmıştır. Gerçekleştirilen gruplandırma Şekil 4’te verilmiştir.

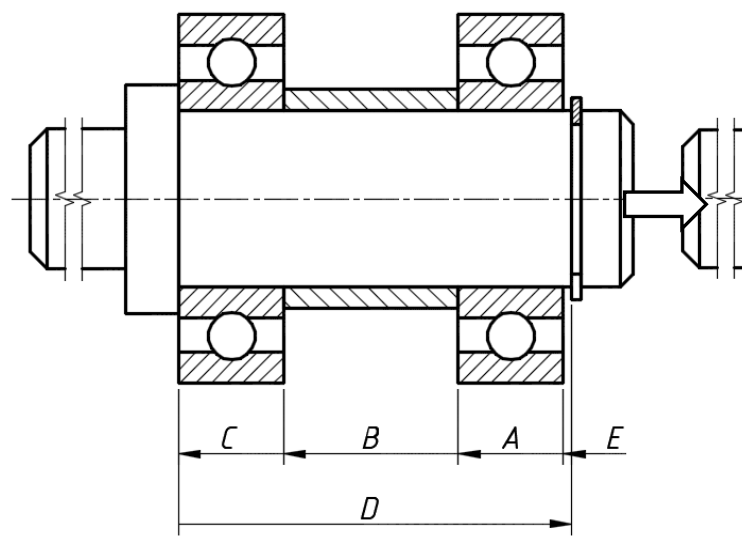

(a)

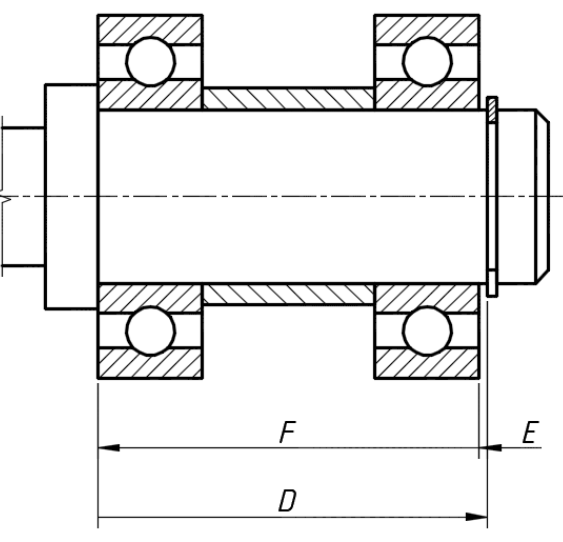

(b)

Şekil 4. Parçaların gruplandırılması

Sistem boyulandırması yapılırken işlem kolaylığı amaçıyla Şekil 4a'da gösterilen birinci rulman (A), burç (B) ve ikinci rulman (C) bir grup haline getirilmiştir. Böylelikle Şekil 3b’de görülen üç nesneli bir yapı elde 
edilmiştir. Bu gruba ait ölçüler ve toleranslar her üç elemanın boyutsal anma ölçüleri ve toleransları toplanarak bulunmuş ve Tablo 4'de sunulmuştur.

Tablo 4. Oluşturulan gruba ait değerler

\begin{tabular}{cccccc}
\hline Parça & Kod & Minimum ölçü (mm) & $\begin{array}{c}\text { Maksimum ölçü } \\
(\mathbf{m m})\end{array}$ & Ortalama ölçü (mm) & Tolerans (mm) \\
\hline Grup & F & 43,430 & 44,000 & 43,715 & 0,285 \\
\hline Mil & D & $?$ & $?$ & $?$ & $?$ \\
\hline Boşluk & E & 0 & 0,600 & 0,300 & 0,300 \\
\hline
\end{tabular}

Gruplandırma işleminden sonra tolerans yığılması işlemi için ilk olarak zincir metodunun ilerleyeceği pozitif yön seçilmiştir. Pozitif yön soldan sağa olarak belirlenmiş (- yön $\leftarrow \rightarrow+$ yön) ve bu durumda mil ölçüsünün değeri araştırılmıştır. En kötü durum senaryosu her koşulda montajı garanti altına almaktadır. Montajı oluşturan tüm parçaların maksimum ölçüleri toplandığında 44,000 mm değeri bulunmaktadır (Tablo 4). Bu durumda en kötü durum senaryosuna göre mil için belirlenebilecek ölçü değerinin en az 44,000 olması gerekmektedir. Bu değer istenen boşluğu üretecek şekilde tolerans verildiğinde mil boyutu 44,000 mm-44,030 mm değerleri arasında olması gerektiği görülmekledir. Tolerans hesaplamalarında kullanılan eşit tolerans dağıtımı yapıldıktan sonra mil için $44,015 \pm 0,015 \mathrm{~mm}$ ölçüsü tespit edilmiştir. Bu hesaplama farklı yoldan da yapılabilir. Grubun tolerans değeri $0,285 \mathrm{~mm}$ olduğundan toplam tolerans değerini $0,300 \mathrm{~mm}$ ölçüsüne çıkartacak olan $0,015 \mathrm{~mm}$ değeri benimsenebilir. Bu işlemin teyidi amacı ile tolerans yığılması değerleri ve bu değerlerin kontrolü Tablo 5 'te görülmektedir.

Tablo 5. Boşluk değerinin tespiti

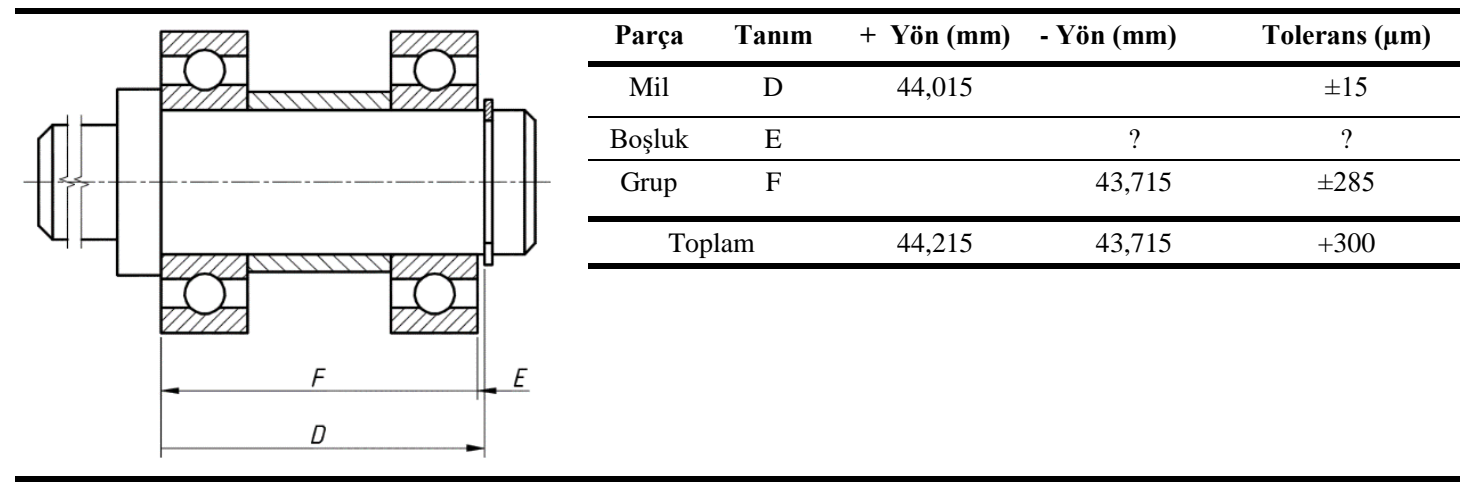

Nominal Ölçü $=\mathrm{E}=$ Pozitif ölçüler - Negatif Ölçüler

Nominal Ölçü $=E=44,015-43,715=0,300$

Tolerans $=300 \mu \mathrm{m}(0,3 \mathrm{~mm}) \rightarrow$ Ölçü $=0,300 \pm 0,300 \mathrm{~mm}$ olmaktadır.

Bu durumda Minimum boşluk = 0,0 mm Maksimum boşluk =0,6 mm olarak hesaplanabilir.

Tablo 5 ve Eşitlik 1-4'teki hesaplamalardan anlaşılacağı gibi her durumda montajı sağlayan ve en fazla 0,6 mm boşluk kalması durumunu içeren en kötü durum senaryosu altında gerekli olan ölçüler 44,000 mm ile 44,030 mm aralığındadır. Bu ölçüye tolerans verildiğinde ise mil ölçüsü 44,015 $\pm 0,015$ mm olarak hesaplanmıştır.

İmalat işlemlerinde toleransların daralması maliyet artışına neden olmaktadır. Bu nedenle istenen şartlara uygun olan en geniş tolerans aralığının tercih edilmesi gereklidir. En kötü durum senaryosunda parçanın imalatı için oldukça dar bir tolerans aralığının belirlendiği ve bunun sonucunda mil maliyetinin de büyük oranda arttıracağı anlaşılmaktadır.

Bir ürünün üretilmesinde tasarımcılar tarafından tolerans verilmediği durumlarda da genel bir tolerans aralığ (ISO 2768) belirlenmektedir. Bu durum yapım resimlerinde mutlaka belirtilmelidir. ISO 2768 standardında artan tolerans aralıkları ile f, m, c ve v olmak üzere 4 tolerans sınıfı belirtilmiştir (Tablo 6). 
Tablo 6. ISO 2768 ölçü toleransları

\begin{tabular}{|l|l|c|c|c|c|c|}
\hline \multicolumn{2}{|c|}{ Tolerans sınıf } & \multicolumn{3}{c|}{ Müsaade edilen sapma miktarları (mm) } \\
\hline \multicolumn{2}{|c|}{} & $\begin{array}{c}\mathbf{0 , 5 - 3} \\
\mathbf{m m} \text { arası }\end{array}$ & $\begin{array}{c}\mathbf{3 - 6} \\
\mathbf{m m} \text { arası }\end{array}$ & $\begin{array}{c}\mathbf{6 - 3 0} \\
\mathbf{m m} \text { arası }\end{array}$ & $\begin{array}{c}\mathbf{3 0 - 1 2 0} \mathbf{~ m m} \\
\text { arası }\end{array}$ & $\begin{array}{c}\mathbf{1 2 0}-\mathbf{4 0 0} \mathbf{~ m m} \\
\text { arası }\end{array}$ \\
\hline f & İnce (fine) & $\pm 0,05$ & 0,05 & $\pm 0,1$ & $\pm 0,15$ & $\pm 0,2$ \\
\hline m & Orta (medium) & $\pm 0,1$ & $\pm 0,1$ & $\pm 0,2$ & $\pm 0,3$ & $\pm 0,5$ \\
\hline c & Kaba (coarse) & $\pm 0,2$ & $\pm 0,3$ & $\pm 0,5$ & $\pm 0,8$ & $\pm 1,2$ \\
\hline v & Çok kaba (very coarse) & - & $\pm 0,5$ & \pm 1 & $\pm 1,5$ & $\pm 2,5$ \\
\hline
\end{tabular}

ISO 2768 genel olarak parçalara verilen tolerans değerlerinden daha büyük aralıklara sahip olduğundan ürün imalatı için ISO 2768 tercih edilen bir tolerans alanı oluşturmaktadır. Bununla birlikte en kötü durum senaryosuna bağlı olarak gerçekleştirilen bu analiz sonucunda elde edilen 44,015 $\pm 0,015 \mathrm{~mm}$ değeri en dar sınıf olan ISO 2768f sınıfına bile girememektedir ve çok dar bir tolerans sınıfı oluşturmaktadır. Bu durumda büyük maliyetlere katlanılması ya da tolerans aralığının genişletilmesi gerekmektedir.

\section{Monte Carlo Simülasyonu}

En kötü durum senaryosunda elde edilen tolerans aralığının darlığı büyük maliyet kayıplarına neden olmaktadır. Bunun için hem istenen fonksiyonu gerçekleştirebilen hem de daha geniş tolerans değer aralıklarını oluşturabilecek bir yöntem arayışına gidilmiştir. Monte Carlo Simülasyonu istatistik temelli bir analizdir [2]. Özellikle seri üretim uygulamalarında istatistiki yaklaşımlar etkin olarak kullanılabilir. Monte Carlo simülasyonu her durumda montajı garanti etmez fakat belirli bir ret oranı ile kabul oranının analizde etkin olarak kullanılabilir. $\mathrm{Bu}$ analizde istatistiki açıdan birçok farklı dağılım türünü uygun olaylara uygulanabilir. Şekil 5'te bir normal dağılım grafiği verilmiştir. Şekil 5'teki Normal dağılım grafiği incelendiğinde, olayların ortalaması olan mod değeri ve medyan değerinin birbirine eşit olduğunu ve eğrinin aritmetik ortalamaya göre simetrik olduğunu gösteren bir dağılım türüdür. Talaşlı imalat üzerine yapılan incelemelerde normal dağılım görülmektedir. Normal dağılım matematiksel olarak Eşitlik 1'de görüldüğü gibi ifade edilmektedir.

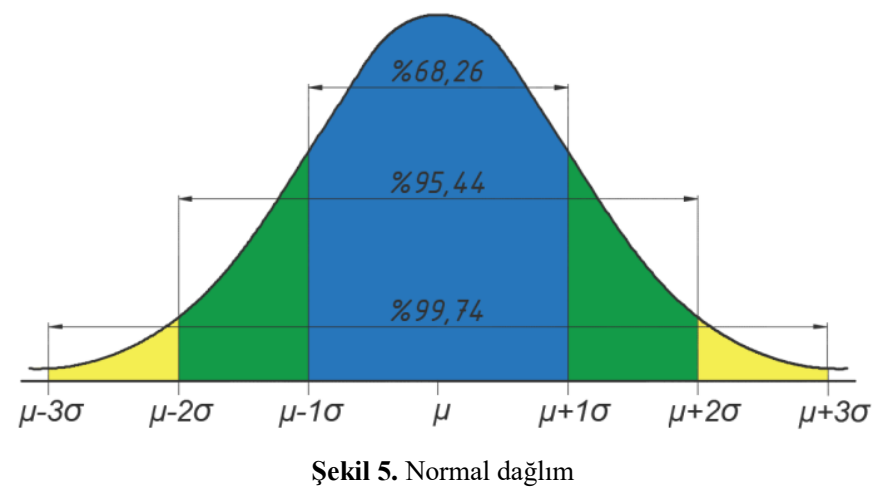

$$
f(x)=\frac{1}{\sigma \sqrt{2 \pi}} e^{-(x-\mu)^{2} /(2 \sigma)^{2}}
$$

$\mathrm{Bu}$ formülde $\sigma$ standart sapmayı, $\mu$ ise aritmetik ortalamayı göstermektedir.

Monte Carlo simülasyonu olasılık teorisine bağlı olarak olasılık kümesinden rastgele sayılar seçme tekniğgidir. Birçok problem türünde etkin olarak kullanabilir bir metottur. Bu metodun uygulanmasında Minitab Workspace yazılımı kullanılmıştır. Monte Carlo simülasyonu ile daha geniş bir tolerans aralığı belirlenerek ve belirli bir hata oranı kabul edilerek bu geniş toleransı sağlayan olasılıklar değerlendirilmiştir. Bu amaçla tüm ölçülerin standart dağılım gösterdiği kabul edilmiş, \%99,7 güven aralığı ile tolerans değerleri 6 ya bölünerek $\sigma$ (standart sapma) değerleri elde edilmiştir. Elde edilen bu değerler Tablo 7'de verilmiştir. 
Tablo 7. $\sigma$ (Standart sapma) değerlerinin hesaplanması

\begin{tabular}{|c|c|c|c|c|}
\hline Parça & Tanım & Ortalama Ölçü (mm) & Tolerans değeri (mm) & $\sigma$ Değeri \\
\hline Rulman 1 & $\mathrm{~A}$ & 11,940 & 0,120 & 0,020 \\
\hline Burç & $\mathrm{B}$ & 19,835 & 0,330 & 0,055 \\
\hline Rulman 2 & $\mathrm{C}$ & 11,940 & 0,120 & 0,020 \\
\hline Mil & $\mathrm{D}$ & 44,015 & 0,030 & 0,005 \\
\hline Boşluk & $\mathrm{E}$ & 0,300 & 0,600 & 0,100 \\
\hline
\end{tabular}

Standart makine elemanları için hesaplanan $\sigma$ değerleri kullanılmıştır. Bununla birlikte mil için daha geniş bir tolerans oluşturacak şekilde standart $\sigma$ değeri yerine kullanılacak $\sigma$ değeri $0,09 \mathrm{~mm}$ olarak tercih edilmiştir. Hesaplama için 50.000 tekrar sayısı kullanılmış ve 50.000 tekrar sonucunda elde edilen sonuçlar Şekil 6'daki dağılım grafiği ile değerlendirilmiştir.

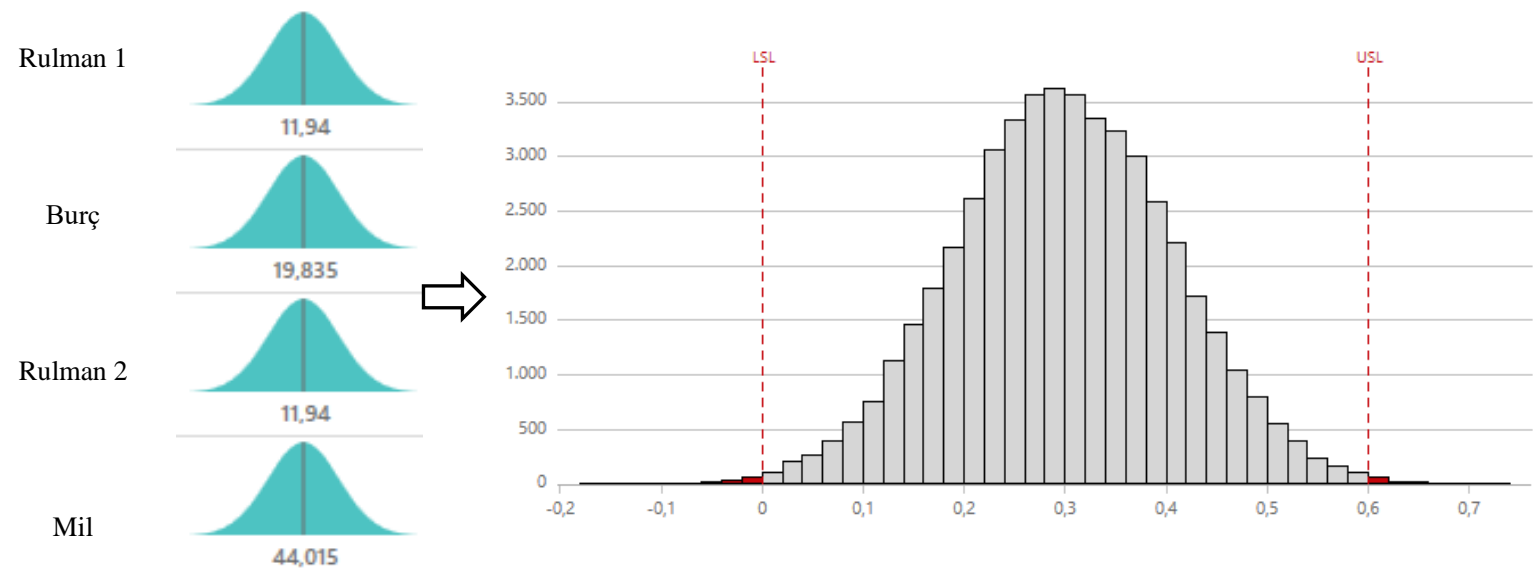

Şekil 6. Rasgele örneklerin dağılımı

Şekil 6'daki grafikler incelendiğinde, tüm montaj ihtimalleri için ret (hata) oranı \%0,55 (Cpk:0,9301) olarak belirlenmiştir. Diğer bir değişle geniş bir tolerans aralığı belirlenmesi durumunda \%0,55 oranında bir hata ile karşılaşılacaktır. Bu durumda \%0,55 ret oranı hata karşılığında standart sapma değeri artarak $\sigma=0,09 \mathrm{~mm}$ ve Tolerans değeri 0,54 mm olacaktır. Bu durumda, mil için nominal ölçünün tolerans değeri 44,015 $\pm 0,27 \mathrm{~mm}$ belirlenmiş böylelikle de mile ait üst ve alt limit değerleri sırası ile 43,745 mm ve 44,285 mm olarak tespit edilmiştir. Bu değerler en kötü durum senaryosu ile karşılaştırıldığında çok daha geniş tolerans aralığı ile çalışmak mümkün hale gelecek ve üretim maliyeti çok aşağı çekilebilecektir. Böylelikle $30 \mathrm{~mm}-120 \mathrm{~mm}$ arası ISO 2768m standarttı değeri olan $\pm 0,2 \mathrm{~mm}$ çok rahat bir şekilde kullanılabilecektir.

\section{SONUÇ VE ÖNERILER}

Yapılan bu çalışmada endüstriyel anlamda büyük öneme sahip olan toleranslandırma konusu araştırılmıştır. $\mathrm{Bu}$ amaçla bir mil ve dört adet standart makine parçasından oluşan bir montaj sistemi analiz edilmiştir. Yapılan analizlerde standart elemanların tolerans değerleri değiştirilemeyeceği için mile tolerans verilmesi en kötü durum senaryosu ve Monte Carlo Simülasyonu ile gerçekleştirilmiştir. Yapılan çalışmanın sonuçları aşağıda özetlenmiştir;

$>$ En kötü durum senaryosuna göre mil sistemi analiz edildiğinde, montajı sağlayacak en yüksek tolerans değeri $\pm 0,015 \mathrm{~mm}$ olarak elde edilmiştir.

> Monte Carlo simülasyonu ile yapılan analiz sonucunda \%0,55 ret oranı kabul edilerek, oldukça yüksek bir tolerans değeri olan 0,27 mm değeri belirlenmiştir. Böylelikle standart üretim sistemleri ISO $2768 \mathrm{~m}$ sınıfına uygun ve üretimi kolaylıkla sağlanabilen bir tolerans sınıfı elde edilmiştir. 
Her iki yöntem karşılaş̧ırıldığında Monte Carlo yöntemi ile çok geniş tolerans aralıklarına ulaşılabileceği anlaşılmıştır. Böylelikle aynı montaj sisteminde ciddi maliyet kazancı elde edilmesi sağlanmıştır.

Sonraki çalışmalarda tolerans aralıklarının geliştirmesi amacıyla farklı yöntemlerin kullanımı incelenebilir. Ayrıca yaylanma özelliğine sahip standart elemanlarla (wave spring) tolerans aralıkları genişletilmesi araştırılabilir.

\section{KAYNAKLAR}

[1] Groover, M.P.(2020).Fundamentals of modern manufacturing: materials, processes, and systems.John Wiley \& Sons, New York, 816.

[2] Fischer, B.R.(2011). Mechanical tolerance stackup and analysis. CRC Press, USA, 508.

[3] Toroslu, A.G. and Börklü H. R.(2009). Gerçekleştirilebilir Toleransların Genetik Algoritma Metodu İle Belirlenmesi. TÜBAV Bilim Dergisi, 2(2): 185-198.

[4] Gültekin, A. and Börklü, H.R. (2001). Tolerans Analiz Yaklaşımları-I: Genel Metodlar, Tolerans Diyagramı ve Graf Teori.Politeknik Dergisi, 4(4): 11-24.

[5] Dantan, J.Y. and Qureshi, A.J. (2009). Worst-case and statistical tolerance analysis based on quantified constraint satisfaction problems and Monte Carlo simulation. Computer-Aided Design, 41(1): 1-12.

[6] Drake Jr, P. (1999). Dimensioning and tolerancing handbook. McGraw-Hill Education.

[7] Bayram, U. and Acar,E. (2015). Tolerance analysis with multiple surrogate models. Acta Phys. Polonica A, 128(2): 447-449.

[8] Saivaew, N. and Butdee, S. (2020). Decision making for effective assembly machined parts selection using fuzzy AHP and fuzzy logic. Materials Today: Proceedings, 26: 2265-2271.

[9] Samtaş, G. and Gülesin, M. (2006). Tolerans Analizinde Yeni Bir Yaklaşım. Politeknik Dergisi, 9(2): 105112.

[10] Chen, H., et al., (2014). A comprehensive study of three dimensional tolerance analysis methods. ComputerAided Design, 53: 1-13.

[11] Hallmann, M., Schleich, B. and Wartzack, S. (2020). How to consider Over-constrained Assemblies with Gaps in Tolerance-Cost Optimization? Procedia CIRP, 92: 88-93.

[12] Kondić, Ž., Đ. Tunjić, and Maglić, L. (2020). Tolerance Analysis of Mechanical Parts.Tehnički glasnik, 14(3): 265-272.

[13] SKF (2021). Deep groove ball bearings.

[14] SKF (2021). Bushing. 